\title{
Article
}

\section{Sustainable Highly Selective Toluene Oxidation to Benzaldehyde}

\author{
Francesca Valentini ${ }^{1}$, Giacomo Ferracci ${ }^{1}$, Pierluca Galloni ${ }^{1}$ (D) Giuseppe Pomarico ${ }^{2}$, Valeria Conte ${ }^{1}$ (D) \\ and Federica Sabuzi ${ }^{1, *(D)}$ \\ 1 Department of Chemical Science and Technologies, University of Rome Tor Vergata, Via della Ricerca \\ Scientifica snc, 00133 Rome, Italy; f.valentini@scienze.uniroma2.it (F.V.); giacomo.ferracci@alice.it (G.F.); \\ galloni@scienze.uniroma2.it (P.G.); valeria.conte@uniroma2.it (V.C.) \\ 2 Department of Molecular and Translational Medicine, University of Brescia, Viale Europa 11, \\ 25123 Brescia, Italy; giuseppe.pomarico@unibs.it \\ * Correspondence: federica.sabuzi@uniroma2.it; Tel.: +39-06-72594490
}

Citation: Valentini, F.; Ferracci, G.;

Galloni, P.; Pomarico, G.; Conte, V.;

Sabuzi, F. Sustainable Highly

Selective Toluene Oxidation to

Benzaldehyde. Catalysts 2021, 11, 262.

https://doi.org/10.3390/catal

11020262

Academic Editors: Francesco Zaccaria and Martin Lamac

Received: 4 February 2021

Accepted: 12 February 2021

Published: 15 February 2021

Publisher's Note: MDPI stays neutral with regard to jurisdictional claims in published maps and institutional affiliations.

Copyright: (C) 2021 by the authors. Licensee MDPI, Basel, Switzerland. This article is an open access article distributed under the terms and conditions of the Creative Commons Attribution (CC BY) license (https:/ / creativecommons.org/licenses/by/ $4.0 /)$

\begin{abstract}
Thanks to the well-recognized role of benzaldehyde in industry, nowadays the research of new and sustainable approaches to selectively synthesize such an interesting product is receiving great attention from the chemists' community. In this paper, a V-based catalytic biphasic system is adopted to perform toluene oxidation to benzaldehyde. Importantly, to pursue sustainability, organic solvents have been avoided, so toluene is used as substrate and co-solvent, together with water. Also, the use of hydrophobic ionic liquids has been explored. To perform oxidation, $\mathrm{NH}_{4} \mathrm{VO}_{3}$ catalyst, $\mathrm{H}_{2} \mathrm{O}_{2}$, and a safe and inexpensive co-catalyst are used. Among the tested co-catalysts, $\mathrm{KF}$ and $\mathrm{O}_{2}$ were found to be the best choice, to guarantee good yields, in mild reaction conditions. In fact, with such a sustainable method, up to $30 \%$ of benzaldehyde can be obtained at $60{ }^{\circ} \mathrm{C}$ and, more interestingly, the oxidative system can be recharged, raising-up the yield. The entire process results highly selective, since no traces of benzyl alcohol or benzoic acid are detected. Hence, it constitutes a very appealing synthetic route, even suitable to be easily scaled-up at an industrial level.
\end{abstract}

Keywords: toluene oxidation; benzaldehyde; vanadium; peroxido-complex; homogeneous catalysis; biphasic system; sustainability; hydrogen peroxide; density functional theory (DFT) calculations; reaction mechanism

\section{Introduction}

Toluene oxidation is currently one of the most important industrial processes: through oxidation, such simple aromatic hydrocarbon can be converted in high added value products, namely benzyl alcohol, benzaldehyde, benzoic acid, and benzoates. The importance of such process resides in toluene oxidation products that are essential molecules, playing a central role in our everyday life. In fact, they are widely used in the manufacture of perfumes, dyes, plasticizers, flame-retardants, preservatives, pesticides, as well as pharmaceuticals [1]. Among the others, benzaldehyde is the most diffused one [2,3], being extensively applied also in food and fragrance industries, as an additive for aroma compositions (due to its bitter almond scent) and as starting material for aliphatic fragrances [4].

Benzaldehyde is a natural product, so it can be easily obtained by extraction or distillation from different botanical sources, like almond, and peach and apricot kernel. However, natural sources are not sufficient to satisfy the market demand, therefore, it is necessary to synthetize benzaldehyde on a large scale, so that its production can exceed 90,000 tons per year globally [5]. Accordingly, in 1887 Étard proposed the first synthetic route to produce benzaldehyde [6]. Thanks to the peculiar high yield and selectivity, such process has been normally used over the years. However, it must be pointed out that Étard reaction occurred in the presence of highly toxic reagents (i.e., $\mathrm{CrO}_{2} \mathrm{Cl}_{2}$ ) and solvents $\left(\mathrm{CCl}_{4}, \mathrm{CS}_{2}\right.$, or $\left.\mathrm{CHCl}_{3}\right)$. Hence, through the years, that process has been entirely replaced. Nowadays the industrial methodology to produce benzaldehyde involves liquid-phase chlorination of toluene, followed by hydrolysis in the presence of a base [7]. Nevertheless, 
harsh working conditions (i.e., the use of halogens at high temperature) and hazardous and corrosive by-products make this process 'environmental unfriendly'. Furthermore, the presence of chlorine contaminants in the product excludes benzaldehyde use in food industry. Also, vapor-phase oxidation has been considered, but it generally produces a large amount of $\mathrm{CO}_{2}$ (as over oxidation product) and several by-products, because of the requested high temperature and high pressure. For these reasons, research of new, sustainable, selective, and industrially attractive synthetic pathways for benzaldehyde production is required.

It is important to highlight that selective synthesis of benzaldehyde is a very challenging task, because of its much easier oxidation aptitude in aerobic conditions with respect to that of toluene [8]. Nevertheless, great efforts have been made to develop suitable catalytic systems for the selective toluene oxidation to benzaldehyde, with a special attention to the sustainability aspect. As an example, homogenous catalysts in combination with ionic liquids [9] or deep eutectic solvents (DES) [10] as reaction media, heterogeneous catalytic systems [11-14], photocatalytic aerobic oxidation $[15,16]$ and electrooxidation in ionic liquids [17] have been reported. Although the majority of these synthetic pathways show good selectivity, efficient catalyst recycling, and safe reaction conditions, the conversion rate is not enough yet to allow an industrial application $[9,15,16]$. Among homogenous catalytic systems, transition metal complexes [18-23], and metal/bromide catalysts [24] have been extensively investigated. Unfortunately, the main issues are still the low conversion rate and the lack of selectivity. Indeed, in many cases, conversion rate increase is accomplished with a decrease in selectivity towards benzaldehyde, due to the formation of benzoic acid and benzyl alcohol. Furthermore, although reaction conditions are defined essentially green by authors, often catalysts synthesis requires multi-step reactions or involves hazardous reagents and solvents, that sensibly raise-up the environmental impact of the whole process [25].

A real breakthrough in benzaldehyde synthesis from toluene was proposed by Pappo's group [26]. Specifically, toluene oxidation was proposed in the presence of $\mathrm{Co}(\mathrm{OAc})_{2}$ ( $2 \mathrm{~mol} \%)$ and $\mathrm{N}$-hydroxyphthalimide (NHPI) $(10 \mathrm{~mol} \%)$ in aerobic condition $\left(\mathrm{O}_{2} 1 \mathrm{~atm}\right)$, using hexafluoropropan-2-ol (HFIP) as solvent. 91\% of toluene conversion and $90 \%$ of selectivity to benzaldehyde were achieved, and authors highlighted the key role of the solvent in preventing over oxidation to benzoic acid. Despite the outstanding results achieved by Pappo's group, an industrial application is still not acceptable.

Quite recently, we have been involved in the study of the oxidative bromination of toluene, using $\mathrm{NH}_{4} \mathrm{VO}_{3}$ as the catalyst [27]. Next to bromination products at the benzylic position, we found that, changing parameters, also benzaldehyde formation could be observed. Such interesting result prompted us to investigate more in detail this uncommon reaction. Therefore, herein, vanadium catalysed toluene oxidation is proposed.

Vanadium is the 20th most abundant element on earth, and it is a relatively non-toxic metal: not surprisingly, it is the 'natural choice' for homogeneous oxygenation/oxidation biocatalytic processes $[28,29]$. Therefore, its use in combination with environmental friendly oxidants, as hydrogen peroxide or molecular oxygen, constitutes a sustainable strategy to perform oxidation reactions. For this reason, Vanadium-based catalysts have been successfully used in oxidation and oxidative bromination of different substrates, with very good results in yield and selectivity [30-36]. As well, toluene oxidative bromination was efficiently performed with the Conte's method using a two-phase system $\left(\mathrm{H}_{2} \mathrm{O}, \mathrm{pH}=1 / \mathrm{CH}_{2} \mathrm{Cl}_{2}\right)$ containing a cheap and safe $\mathrm{V}$-salt (i.e., $\left.\mathrm{NH}_{4} \mathrm{VO}_{3}\right), \mathrm{H}_{2} \mathrm{O}_{2}$ and $\mathrm{KBr}$. The most relevant feature of such approach is that the reaction occurred in a biphasic system, where water was the medium to dissolve all the reagents, and chloroform or dichloromethane were needed as co-solvent to dissolve the substrate.

In this work, toluene oxidation is presented, exploiting the same experimental conditions, but avoiding the use of chlorinated solvents, with the aim to raise-up the sustainability of the process. Hence, toluene is used as substrate and co-solvent at the same time. Additionally, $\mathrm{KF}$ is adopted as inorganic salt to replace $\mathrm{KBr}$, in order to avoid formation of 
brominated products (Scheme 1). As a matter of fact, the use of such a green system may constitute an appealing approach to selectively achieve toluene oxidation.

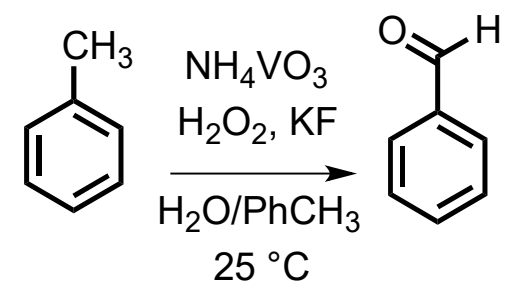

Scheme 1. Toluene oxidation in a biphasic system.

\section{Results and Discussion}

Toluene oxidation reaction was initially explored by varying $\mathrm{NH}_{4} \mathrm{VO}_{3}$ and $\mathrm{H}_{2} \mathrm{O}_{2}$ amounts, inorganic salt nature and quantity, and temperature. As well, it was performed either under $\mathrm{O}_{2}$ or $\mathrm{N}_{2}$ atmosphere. Importantly, in such conditions, toluene oxidation occurs at the interphase between the aqueous media and the organic solvent, hence a powerful stirring $(\geq 1000$-rpm) in a large flask is required.

Product analysis was carried out after the complete $\mathrm{H}_{2} \mathrm{O}_{2}$ consumption (usually 4 or $24 \mathrm{~h}$, as checked with the iodide starch paper test). Interestingly, in all experiments, chemospecific formation of benzaldehyde was detected by GC-MS analysis. In fact, no overoxidation products were found. It is important to underline that, being toluene used in large excess, yields have been calculated with respect to $\mathrm{H}_{2} \mathrm{O}_{2}$, i.e., the limiting reagent in the mixture. Results are summarized in Table 1.

Table 1. Toluene oxidation in biphasic system ( $\left.\mathrm{V}=20 \mathrm{~mL} ; \mathrm{PhCH}_{3}: \mathrm{H}_{2} \mathrm{O} 1: 1 v / v\right), \mathrm{pH}=1,24 \mathrm{~h}, \mathrm{~T}=25^{\circ} \mathrm{C}$.

\begin{tabular}{|c|c|c|c|c|c|}
\hline Entry & $\mathrm{H}_{2} \mathrm{O}_{2}(\mathrm{mmol})$ & $\mathrm{VO}_{3}^{-}(\mathrm{mmol})$ & KF (mmol) & Benzaldehyde $\left({ }^{*} 10^{-3} \mathrm{mmol}\right)$ & Yield (\%) \\
\hline 1 & 0.2 & 0.02 & 0.25 & 5.0 & 3 \\
\hline 2 & $0.1+0.1^{1}$ & 0.02 & 0.25 & 3.0 & 2 \\
\hline 3 & 0.2 & 0.10 & 0.25 & 20.0 & 10 \\
\hline 4 & $0.1+0.1^{1}$ & 0.10 & 0.25 & 22.0 & 11 \\
\hline 5 & 0.2 & 0.20 & 0.25 & 4.0 & 2 \\
\hline 6 & 0.05 & 0.05 & 0.25 & 7.5 & $15^{2}$ \\
\hline 7 & 0.05 & 0.025 & 0.25 & 3.0 & 8 \\
\hline 8 & 0.05 & 0.05 & - & - & - \\
\hline
\end{tabular}

${ }^{1}$ Added after 4 h. ${ }^{2}$ Calculated after $4 \mathrm{~h}$.

Toluene oxidation performed with $10 \%$ of $\mathrm{NH}_{4} \mathrm{VO}_{3}$ with respect to $\mathrm{H}_{2} \mathrm{O}_{2}$ selectively led to the formation of benzaldehyde, but yields were not satisfactory (entries 1,2). Raisingup the amount of the vanadium salt to $50 \%$ (entries 3,4) increased significantly benzaldehyde yield. Because of the concomitant vanadium catalysed $\mathrm{H}_{2} \mathrm{O}_{2}$ decomposition, stepwise addition of the oxidant was performed not achieving better performances. Conversely, working with equimolar amount of $\mathrm{NH}_{4} \mathrm{VO}_{3}$ and $\mathrm{H}_{2} \mathrm{O}_{2}$ led to a drastic drop of the yield (entry 5). Likely, in these conditions, hydrogen peroxide degradation was faster than toluene oxidation. So reagents concentration in solution was decreased: $15 \%$ of benzaldehyde after only $4 \mathrm{~h}$ was detected working with $0.05 \mathrm{mmol}$ of both $\mathrm{H}_{2} \mathrm{O}_{2}$ and $\mathrm{NH}_{4} \mathrm{VO}_{3}$. Furthermore, the reaction with $50 \%$ of vanadium with respect to $\mathrm{H}_{2} \mathrm{O}_{2}$ showed a decrease of the yield (entry 7). To establish the role of the inorganic salt, a blank experiment in the absence of KF was performed but neither benzaldehyde nor other products were detected (entry 8).

Despite the promising yield accomplished using toluene as solvent and substrate (15\%, Table 1 entry 6$)$, its conversion was still too low to be considered acceptable in a sustainable modern process. Therefore, inspired by previous results with similar systems [37], the reaction was performed adding a stoichiometric amount of the substrate with respect to $\mathrm{H}_{2} \mathrm{O}_{2}$, in water (Table 2). 
Table 2. Toluene oxidation in $\mathrm{H}_{2} \mathrm{O}, \mathrm{pH}=1, \mathrm{~T}=25^{\circ} \mathrm{C}, 24 \mathrm{~h}$.

\begin{tabular}{cccccc}
\hline Entry & Toluene $(\mathbf{m m o l})$ & $\mathbf{H}_{\mathbf{2}} \mathbf{O}_{\mathbf{2}} \mathbf{( \mathbf { m m o l } )}$ & $\mathbf{V O}_{\mathbf{3}}{ }^{-} \mathbf{( \mathbf { m m o l } )}$ & $\mathbf{K F} \mathbf{( m m o l )}$ & Yield $\mathbf{( \% )}$ \\
\hline 1 & 0.05 & 0.05 & 0.05 & 0.25 & 1 \\
2 & 0.5 & 0.05 & 0.05 & 0.25 & 1 \\
3 & 0.5 & 0.5 & 0.05 & 0.25 & 1 \\
4 & 0.5 & 0.05 & 0.05 & 0.25 & $12^{1}$ \\
$5^{2}$ & 0.5 & 0.05 & 0.05 & 0.25 & 0 \\
$6^{3}$ & 0.5 & 0.05 & 0.05 & 0.25 & 0.5 \\
$7^{4}$ & 0.5 & 0.05 & 0.05 & 0.25 & 24 \\
\hline
\end{tabular}

${ }^{1}$ Calculated after $48 \mathrm{~h} ;{ }^{2}$ Solvent: dichloromethane: $\mathrm{H}_{2} \mathrm{O}$ 1:1 v:v; total volume $=20 \mathrm{~mL}^{3}$ Solvent: cyclohexane: $\mathrm{H}_{2} \mathrm{O}$ $1: 1 \mathrm{v}: \mathrm{v} ;$ total volume $=20 \mathrm{~mL}$; yield calculated after $4 \mathrm{~h} ;{ }^{4}$ Solvent: $[\mathrm{pmim}] \mathrm{Tf}_{2} \mathrm{~N}: \mathrm{H}_{2} \mathrm{O} 1: 10 \mathrm{v}: \mathrm{v}$; total volume $=11 \mathrm{~mL}$

Yet, performing reactions with a stoichiometric amount of toluene in a large flask, with a condenser on the top, caused substrate loss: at the end of the reaction, only $1 \%$ of benzaldehyde was detected in the mixture, while toluene almost completely disappeared (entries $1-3)$. Hence, reaction was repeated in a closed vessel achieving $12 \%$ of benzaldehyde after $48 \mathrm{~h}$ (entry 4). Although yield was encouraging, result was not acceptable yet. Therefore, a classical two-phase system was exploited [30]: toluene was dissolved in $\mathrm{CH}_{2} \mathrm{Cl}_{2}$ (entry 5) or cyclohexane (entry 6), a more sustainable alternative to the chlorinated solvent. In both cases, no reaction was observed. Inspired by the excellent results achieved in previous studies $[32,38,39]$, a hydrophobic ionic liquid (i.e., [pmim] $\mathrm{Tf}_{2} \mathrm{~N}$ 1-propyl-3-methylimidazolium bis(trifluoromethylsulfonyl)imide) was adopted as co-solvent. In fact, in the last years ionic liquids became a valid alternative to the conventional molecular solvents, due to their unique properties such as non-volatility, high thermal stability and reusability [40]. $0.5 \mathrm{mmol}$ of toluene were dissolved in $1 \mathrm{~mL}$ of [pmim] $\mathrm{Tf}_{2} \mathrm{~N} ; 10 \mathrm{~mL}$ of an aqueous solution containing $\mathrm{NH}_{4} \mathrm{VO}_{3}$ were then added, with $\mathrm{H}_{2} \mathrm{O}_{2}$ and $\mathrm{KF}$. After $24 \mathrm{~h}, 24 \%$ of benzaldehyde was detected in the mixture, together with traces of the benzyl alcohol.

The best compromise, hitherto, in terms of yield and selectivity remains the one achieved using toluene as substrate-solvent, where $15 \%$ yield of benzaldehyde was obtained after only $4 \mathrm{~h}$ (Table 1, entry 6 ). Therefore, such conditions have been adopted to investigate the process by changing inorganic salt, atmosphere composition and temperature.

Importantly, the blank experiment without KF (Table 1, entry 8) showed that such inorganic salt is pivotal to obtain benzaldehyde. To confirm such evidence, other different inorganic salts were screened, with the aim to increase yield and to understand the salt role in the reaction mechanism. However, KF remained the best choice, since no improvement was observed varying the nature of cation or anion (Table 3).

Table 3. Toluene oxidation in biphasic system $\left(\mathrm{V}=20 \mathrm{~mL} ; \mathrm{PhCH}_{3}: \mathrm{H}_{2} \mathrm{O}\right.$ 1:1 v/v), $\mathrm{pH}=1$, $\mathrm{H}_{2} \mathrm{O}_{2} 0.05 \mathrm{mmol}, \mathrm{NH}_{4} \mathrm{VO}_{3} 0.05 \mathrm{mmol}$, salt $0.25 \mathrm{mmol}, 24 \mathrm{~h}, \mathrm{~T}=25^{\circ} \mathrm{C}$.

\begin{tabular}{ccc}
\hline Entry & Salt & Yield (\%) \\
\hline 1 & $\mathrm{KF}$ & 15 \\
2 & $\mathrm{LiF}$ & 12 \\
3 & $\mathrm{NaF}$ & 10 \\
4 & $\mathrm{CsF}$ & 11 \\
5 & $\mathrm{TBAF}$ & 10 \\
6 & $\mathrm{NaCl}$ & 3 \\
7 & $\mathrm{KCl}$ & 4 \\
8 & $\mathrm{KBr}$ & 19 \\
\hline
\end{tabular}

Notably, with $\mathrm{KBr}$, a slight increase of benzaldehyde yield was observed, probably because of the presence of $\mathrm{Br}^{-}$ions in solution, which hamper the radical degradation of $\mathrm{H}_{2} \mathrm{O}_{2}$ usually occurring in the presence of vanadium (entry 8) [41,42]. Such effect results in an increasing amount of $\mathrm{H}_{2} \mathrm{O}_{2}$ available for toluene oxidation. However, with $\mathrm{KBr}$, also bromination products were obtained in good yields [27]. Therefore, KF is the best compromise between yield and selectivity. 
KF concentration in the reaction mixture was then varied (Table 4).

Table 4. Toluene oxidation in biphasic system $\left(\mathrm{V}=20 \mathrm{~mL} ; \mathrm{PhCH}_{3}: \mathrm{H}_{2} \mathrm{O} 1: 1 \mathrm{v} / \mathrm{v}\right), \mathrm{pH}=1,24 \mathrm{~h}, \mathrm{~T}=25^{\circ} \mathrm{C}$.

\begin{tabular}{|c|c|c|c|c|c|}
\hline Entry & $\mathrm{H}_{2} \mathrm{O}_{2}(\mathrm{mmol})$ & $\mathrm{VO}_{3}^{-}(\mathrm{mmol})$ & KF (mmol) & Benzaldehyde $\left({ }^{*} 10^{-3} \mathrm{mmol}\right)$ & Yield (\%) \\
\hline 1 & 0.05 & 0.05 & 0.05 & 10.0 & 20 \\
\hline 2 & 0.05 & 0.025 & 0.05 & 5.4 & 11 \\
\hline 3 & 0.05 & 0.025 & 0.025 & 9.4 & 19 \\
\hline 4 & 0.05 & 0.01 & 0.01 & 1.5 & 4 \\
\hline
\end{tabular}

Results showed that an equimolar amount of $\mathrm{NH}_{4} \mathrm{VO}_{3}$ and $\mathrm{KF}$ was necessary to attractively form benzaldehyde. In particular, working with $0.025 \mathrm{mmol}$ of both (entry 3), $19 \%$ yield of benzaldehyde was obtained after $24 \mathrm{~h}$.

In an attempt to further improve yield and to understand reaction mechanism, toluene oxidation was carried out also under $\mathrm{O}_{2}$ or $\mathrm{N}_{2}$ atmosphere (Table 5).

Table 5. Toluene oxidation in biphasic system $\left(\mathrm{V}=20 \mathrm{~mL} ; \mathrm{PhCH}_{3}: \mathrm{H}_{2} \mathrm{O} 1: 1 \mathrm{v} / \mathrm{v}\right), \mathrm{pH}=1,24 \mathrm{~h}, \mathrm{~T}=25^{\circ} \mathrm{C}, \mathrm{O}_{2}$.

\begin{tabular}{|c|c|c|c|c|c|}
\hline Entry & $\mathrm{H}_{2} \mathrm{O}_{2}(\mathrm{mmol})$ & $\mathrm{VO}_{3}^{-}(\mathrm{mmol})$ & KF (mmol) & Benzaldehyde $\left({ }^{*} 10^{-3} \mathrm{mmol}\right)$ & Yield (\%) \\
\hline 1 & 0.05 & 0.05 & 0.05 & 13.0 & 33 \\
\hline 2 & 0.05 & 0.05 & - & 19.4 & 40 \\
\hline 3 & 0.05 & 0.025 & - & 15.0 & 30 \\
\hline 4 & 0.05 & 0.01 & & 1.7 & 5 \\
\hline 5 & - & 0.05 & - & - & - \\
\hline
\end{tabular}

Interestingly, under $\mathrm{O}_{2}$ atmosphere, a significant increase of the yield was observed. Indeed, up to $33 \%$ of benzaldehyde was obtained (entry 1 ). To note, working in the absence of $\mathrm{KF}$, but using $0.05 \mathrm{mmol}$ of both $\mathrm{NH}_{4} \mathrm{VO}_{3}$ and $\mathrm{H}_{2} \mathrm{O}_{2}$ in the presence of dioxygen led to a remarkable yield (40\%, entry 2). If $50 \%$ of $\mathrm{NH}_{4} \mathrm{VO}_{3}$ was used with respect to $\mathrm{H}_{2} \mathrm{O}_{2}, 30 \%$ of benzaldehyde was obtained (entry 3). Conversely, reactions performed with $20 \%$ of $\mathrm{NH}_{4} \mathrm{VO}_{3}$ with respect to the oxidant (entry 4) or in the absence of $\mathrm{H}_{2} \mathrm{O}_{2}$ (entry 5 ) were not successful. Under $\mathrm{N}_{2}$ atmosphere, using the standard conditions reported in Table 1 , entry 6 , a decrease in benzaldehyde conversion was observed, obtaining $12 \%$ of benzaldehyde.

Thus likely, in this process, hydrogen peroxide is the actual oxidant, being involved in the formation of the vanadium(V)-peroxido complex [43], while $\mathrm{O}_{2}$ and $\mathrm{KF}$ have a promoting effect in the oxidation of toluene.

Attempting to increase benzaldehyde yield, temperature and reaction time were changed (Figure 1, Table S1).

Working with an equimolar amount of $\mathrm{H}_{2} \mathrm{O}_{2}$ and $\mathrm{NH}_{4} \mathrm{VO}_{3}$, in the presence of $\mathrm{KF}$ led to $22 \%$ yield after $72 \mathrm{~h}$ at $25^{\circ} \mathrm{C}$. Increasing the temperature to $40{ }^{\circ} \mathrm{C}$, produced a $28 \%$ yield in $72 \mathrm{~h}$, while at $60^{\circ} \mathrm{C}$ the same amount of benzaldehyde was obtained after only $24 \mathrm{~h}$. Consequently, in order to increase the catalyticity, reactions were carried out at $60^{\circ} \mathrm{C}$, decreasing the amount of the $\mathrm{V}(\mathrm{V})$-salt.

To note, an appreciable yield of $28 \%$ was obtained using $20 \%$ of $\mathrm{NH}_{4} \mathrm{VO}_{3}$ under dioxygen at $60^{\circ} \mathrm{C}$ (Table 6, entry 3). The same result was attained in the presence of KF (Table 6, entry 4). To recap, the best performances were obtained with $50 \% \mathrm{NH}_{4} \mathrm{VO}_{3}$ at $25^{\circ} \mathrm{C}$ (Table 5, entry 3), or $20 \% \mathrm{NH}_{4} \mathrm{VO}_{3}$ at $60{ }^{\circ} \mathrm{C}$ (Table 6, entry 3) both under $\mathrm{O}_{2}$ atmosphere. 


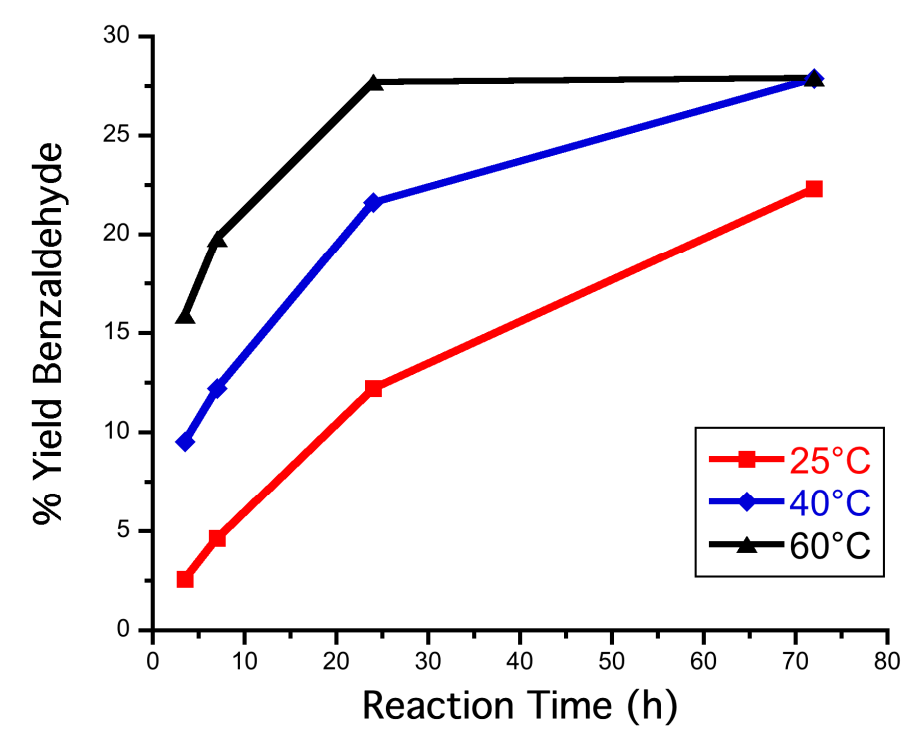

Figure 1. Toluene oxidation in biphasic system $\mathrm{PhCH}_{3}-\mathrm{H}_{2} \mathrm{O}$ at different temperatures: (red) $25^{\circ} \mathrm{C}$, (blue) $40{ }^{\circ} \mathrm{C}$, (black) $60{ }^{\circ} \mathrm{C}$. Conditions: $\mathrm{V}=20 \mathrm{~mL} ; \mathrm{PhCH}_{3}: \mathrm{H}_{2} \mathrm{O} 1: 1 \mathrm{v} / \mathrm{v}, \mathrm{pH}=1, \mathrm{H}_{2} \mathrm{O}_{2} 0.05 \mathrm{mmol}$, $\mathrm{NH}_{4} \mathrm{VO}_{3} 0.05 \mathrm{mmol}, \mathrm{KF}=0.25 \mathrm{mmol}$.

Table 6. Toluene oxidation under air and $\mathrm{O}_{2}$ atmosphere in a biphasic system $\mathrm{PhCH}_{3}-\mathrm{H}_{2} \mathrm{O}\left(\mathrm{V}=20 \mathrm{~mL} ; \mathrm{PhCH}_{3}: \mathrm{H}_{2} \mathrm{O} 1: 1 v / v\right)$, $\mathrm{pH}=1$, after $24 \mathrm{~h}$, at $60^{\circ} \mathrm{C}$.

\begin{tabular}{|c|c|c|c|c|c|c|}
\hline Entry & Atmosphere & $\mathrm{H}_{2} \mathrm{O}_{2}(\mathrm{mmol})$ & $\mathrm{VO}_{3}-(\mathrm{mmol})$ & KF (mmol) & Benzaldehyde $\left({ }^{*} 10^{-3} \mathrm{mmol}\right)$ & Yield $(\%)$ \\
\hline 1 & $\mathrm{O}_{2}$ & 0.05 & 0.025 & - & 15.4 & 31 \\
\hline 2 & air & 0.05 & 0.025 & 0.025 & 16.3 & 33 \\
\hline 3 & $\mathrm{O}_{2}$ & 0.05 & 0.01 & - & 14.0 & 28 \\
\hline 4 & air & 0.05 & 0.01 & 0.01 & 14.6 & 28 \\
\hline
\end{tabular}

It is important to stress out that, after $24 \mathrm{~h}, \mathrm{H}_{2} \mathrm{O}_{2}$ and $\mathrm{HClO}_{4}$ total consumption is usually observed. Therefore, the possibility to recharge $\mathrm{H}_{2} \mathrm{O}_{2}$ and $\mathrm{HClO}_{4}$, thus restoring the $\mathrm{V}(\mathrm{V})$-monoperoxido complex in solution was explored, taking advantage from the two-phase system (water/toluene). The recyclability assays were carried out using the optimized reaction conditions reported (Table 5, entry 3 and Table 6, entry 3 ). Four additions have been performed every $24 \mathrm{~h}$; at each round, benzaldehyde quantification has been carried out. Regarding the system at $25{ }^{\circ} \mathrm{C}$ (Figure 2, Table S2) a significant increase in benzaldehyde formation was observed after the second addition, i.e., round 2.

Indeed, up to $25 \times 10^{-3} \mathrm{mmol}$ of benzaldehyde were obtained, with a round yield of $30 \%$ and an overall yield of $25 \%$. The third and fourth additions did not cause an appreciable improvement in benzaldehyde production. In fact, throughout third and fourth round, a plateau was reached, and consequently a decrease of the overall yield was observed. On the other hand, the reaction performed with $20 \%$ of $\mathrm{NH}_{4} \mathrm{VO}_{3}$ at $60{ }^{\circ} \mathrm{C}$ continuously produced benzaldehyde after each oxidant addition. (Figure 3, Table S3) 


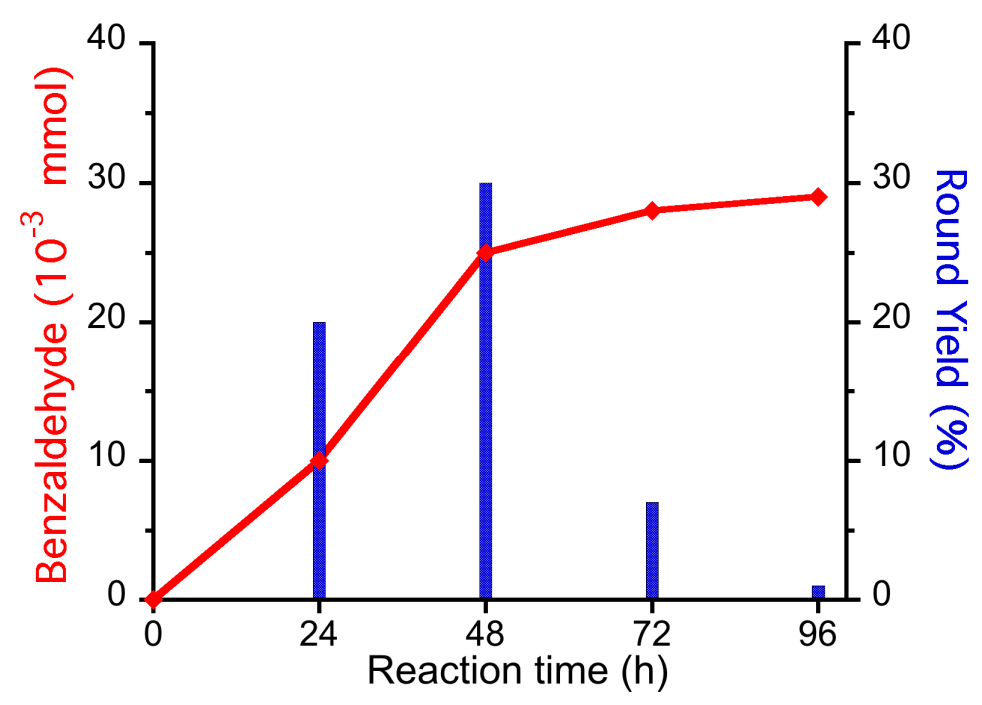

Figure 2. Recycle tests for the selective toluene oxidation to benzaldehyde under $\mathrm{O}_{2}$ atmosphere in a biphasic system $\mathrm{PhCH}_{3}-\mathrm{H}_{2} \mathrm{O}$. Conditions: $\mathrm{V}=20 \mathrm{~mL} ; \mathrm{PhCH}_{3}: \mathrm{H}_{2} \mathrm{O} 1: 1 \mathrm{v} / \mathrm{v}, \mathrm{pH}=1, \mathrm{H}_{2} \mathrm{O}_{2} 0.05 \mathrm{mmol}$, $\mathrm{NH}_{4} \mathrm{VO}_{3} 0.025 \mathrm{mmol}$ at $25^{\circ} \mathrm{C}$.

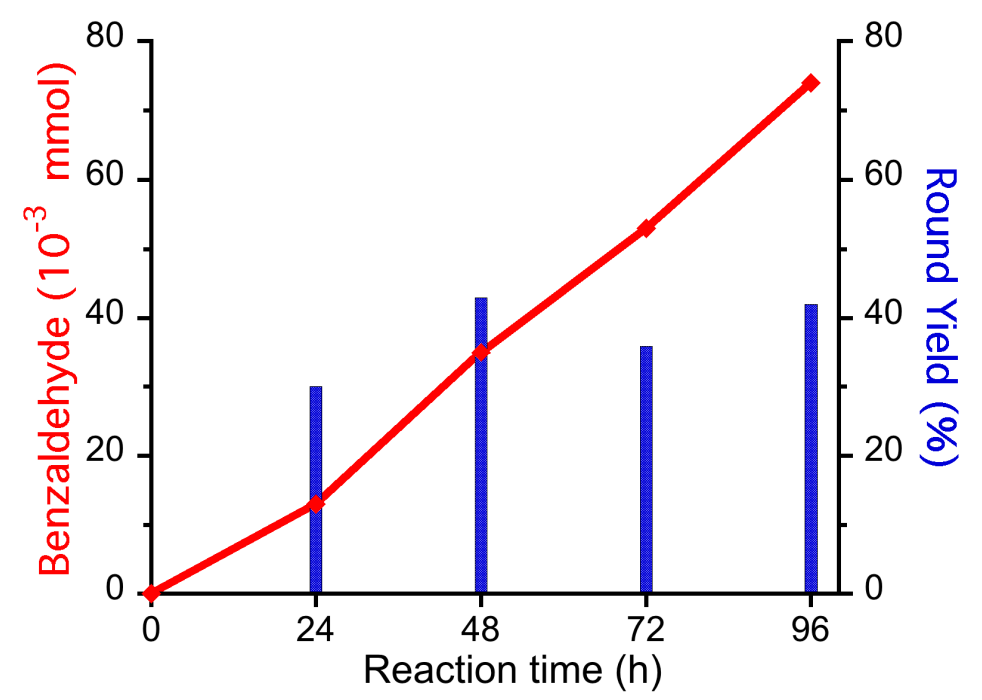

Figure 3. Recycle tests for the selective toluene oxidation to benzaldehyde under $\mathrm{O}_{2}$ atmosphere in a biphasic system $\mathrm{PhCH}_{3}-\mathrm{H}_{2} \mathrm{O}$. Conditions: $\mathrm{V}=20 \mathrm{~mL} ; \mathrm{PhCH}_{3}: \mathrm{H}_{2} \mathrm{O}$ 1:1 v/v, $\mathrm{pH}=1, \mathrm{H}_{2} \mathrm{O}_{2} 0.05$ mmol, $\mathrm{NH}_{4} \mathrm{VO}_{3} 0.01 \mathrm{mmol}$ at $60^{\circ} \mathrm{C}$.

Remarkably, at the end of the fourth round, $74 \times 10^{-3} \mathrm{mmol}$ of benzaldehyde were detected in solution, with a constant round yield and an overall yield of $37 \%$. Such an exciting result opens the possibility to continuously add $\mathrm{H}_{2} \mathrm{O}_{2}$ to the solution, likely fully converting toluene.

From a mechanistic point of view, in the adopted experimental conditions, the Vcatalysed toluene oxidation likely occurs through a radical pathway. Therefore, a plausible catalytic cycle has been proposed (Figure 4). 


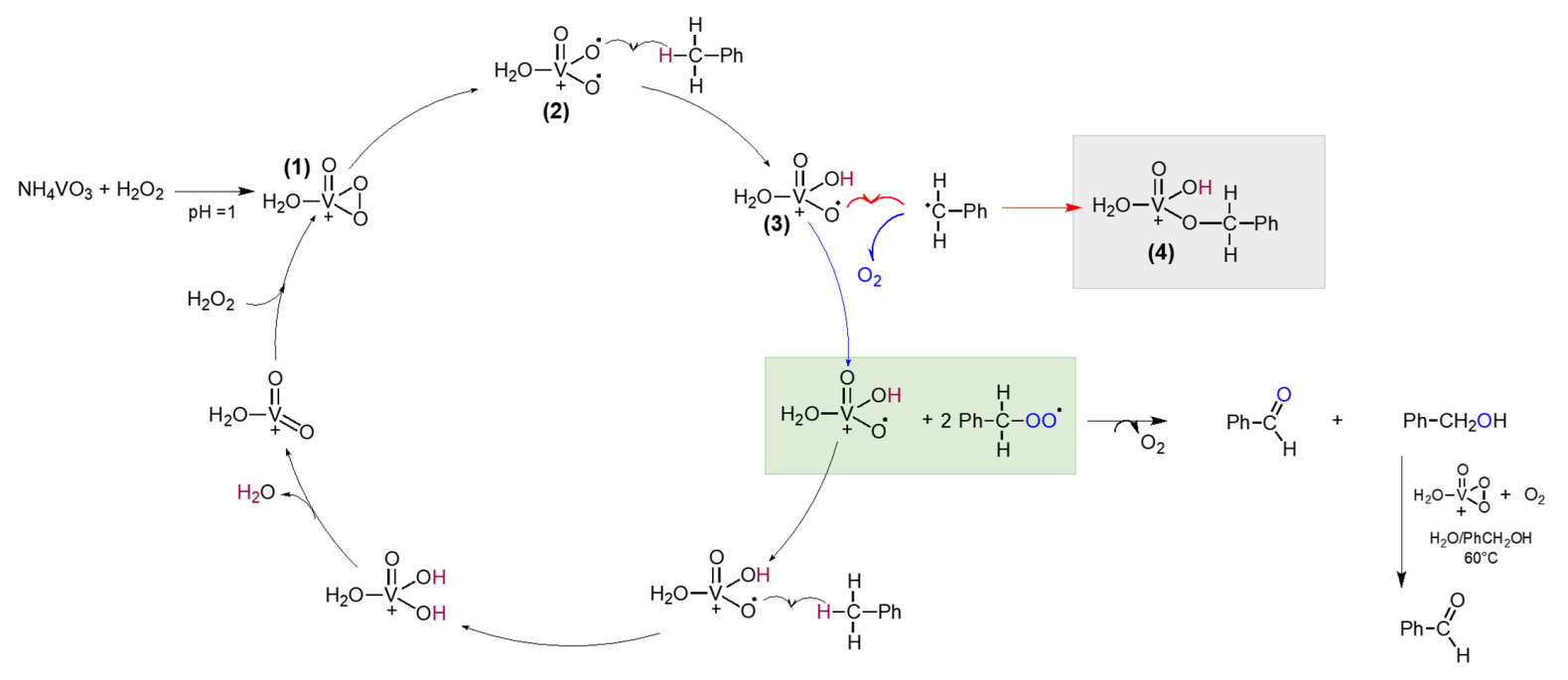

Figure 4. Proposed catalytic cycle for toluene oxidation to benzaldehyde.

In fact, it is already well established that the dissolution of $\mathrm{NH}_{4} \mathrm{VO}_{3}$ in acid water $(\mathrm{pH}=1)$ containing $\mathrm{H}_{2} \mathrm{O}_{2}$ leads to the formation of a vanadium (V) peroxido-complex (1), which is a very effective oxidant $[34,43,44]$. In the first step of the cycle, the homolytic cleavage of the $\mathrm{O}-\mathrm{O}$ bond possibly occurs, forming the radical V-complex (2), that can abstract $\mathrm{a} \mathrm{H}^{\bullet}$ from toluene in solution, thus forming vanadium complex (3) and benzyl radical. The latter can react in two different pathways: with complex (3) itself, to form $\mathrm{V}$-complex (4) in a non-productive way, or it can react with $\mathrm{O}_{2}$ in solution, to obtain the benzyl peroxy radical. The coupling of two benzyl peroxy radicals forms benzaldehyde, benzyl alcohol and $\mathrm{O}_{2}$ through a well-established mechanism [45]. The formed by-product, namely benzyl alcohol, is then immediately oxidized to benzaldehyde through a similar radical pathway, passing through $\mathrm{H}$-abstraction from the $\mathrm{OH}$ group.

As a matter of fact, due to the higher reactivity of benzyl alcohol with respect to toluene, it has never been detected as by-product, since it is readily converted to benzaldehyde. As a verification, benzyl alcohol oxidation in the optimised experimental conditions $\left(\mathrm{H}_{2} \mathrm{O}_{2}=0.05 \mathrm{mmol} ; \mathrm{NH}_{4} \mathrm{VO}_{3}=0.01 \mathrm{mmol} ; \mathrm{T}=60^{\circ} \mathrm{C} ; \mathrm{O}_{2}\right)$ selectively produces benzaldehyde .

Notably, in the presence of $\mathrm{KF}$, fluoride coordination to vanadium likely occurs, leading to V-fluorooxoperoxido complex [46,47]. UV-vis absorption spectrum of V-monoperoxido complex in aqueous solution shows appreciable variations in the presence of KF, possibly supporting fluoride coordination to vanadium (Figure S1). However, due to the reported instability, such V-species have not been isolated and further characterized, therefore, no experimental verification about their structure in solution have been obtained. For this reason, such complexes have not been included in further mechanistic studies.

To better explicate the mechanism, DFT calculations have been carried out, using Gaussian 16 rev. A.03. Geometry optimization of reagents, intermediates and transition states (TS) has been performed in vacuum using B3LYP functional. 6-31G(d) basis set was used for $\mathrm{H}, \mathrm{C}$, and $\mathrm{O}$ atoms, while LanL2DZ basis set was adopted for vanadium [48]. The relative energy diagram vs. reaction coordinate is represented in Figure 5. 


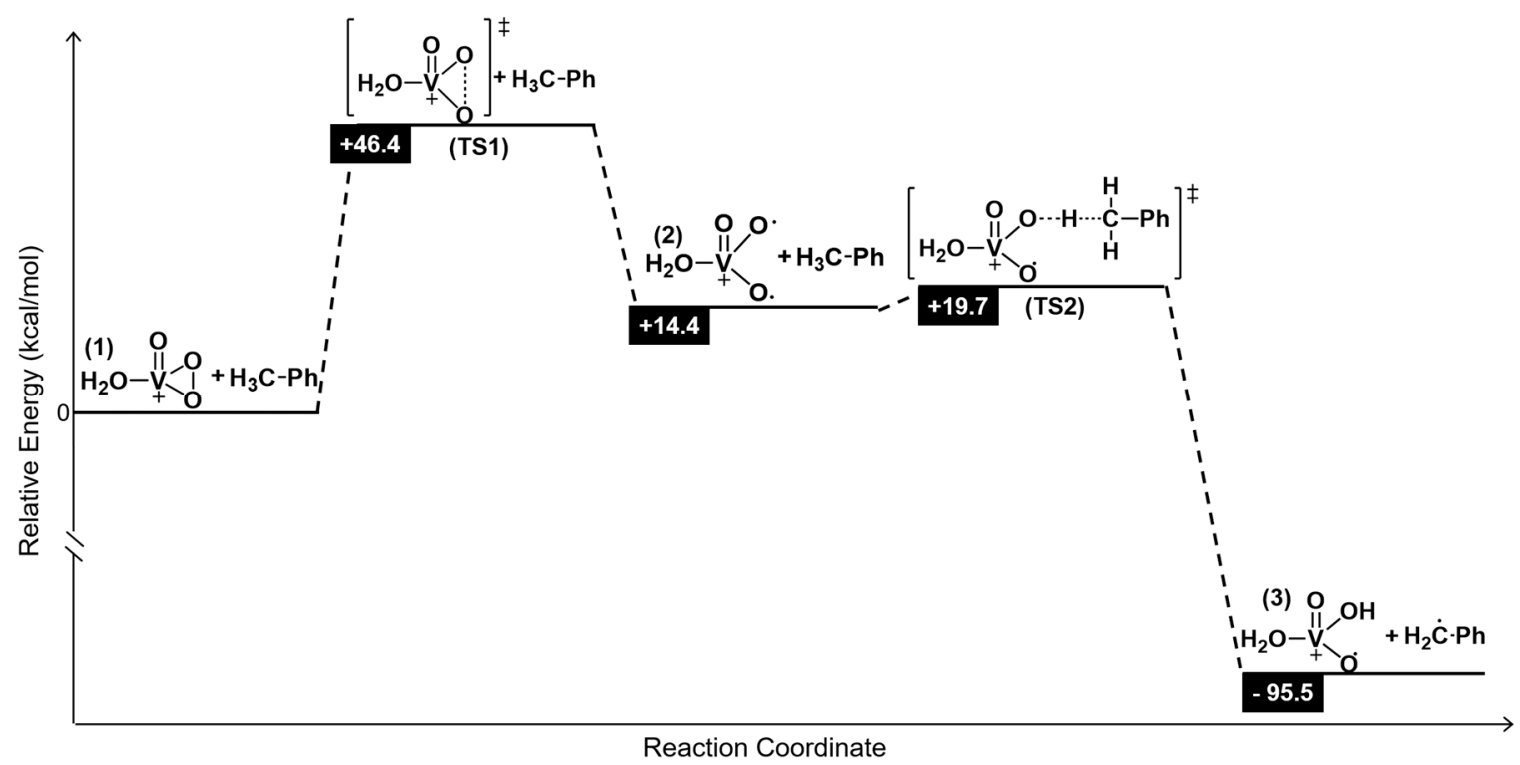

Figure 5. Relative energy diagram vs. reaction coordinate.

In the adopted experimental conditions, tetrahedral V-monoperoxido complex (1) is the catalytically active species in solution. Importantly, the positively charged complex (1) has been modelled with one water molecule coordinated to the V-center, being this species the most abundant one experimentally observed [43]. V=O, $\mathrm{V}-\mathrm{O}$ and $\mathrm{O}-\mathrm{O}$ distances have been calculated and they resulted in line with previously published data (calculated distances = $1.56 \AA, 1.77 \AA$ and $1.42 \AA$, respectively) [49]. Calculations clearly indicate that the first step is the rate determining one, since the activation energy to form complex (2) is $46.4 \mathrm{kcal} \cdot \mathrm{mol}^{-1}$ (Figure 5). In fact, in the first step, the homolytic cleavage of O-O bond occurs, leading to the vanadium diradical species (2) (calculated $\mathrm{O}-\mathrm{O}$ distance $=$ $2.89 \AA), 14.4 \mathrm{kcal} \cdot \mathrm{mol}^{-1}$ higher in energy than (1). At this stage, H-abstraction from toluene is predictable, to form benzyl radical and tetrahedral V-radical complex (3), thus gaining a significant stabilization of the system (relative energy $=-95.5 \mathrm{kcal} \cdot \mathrm{mol}^{-1}$ ). Here, the activation energy barrier resulted about $5.3 \mathrm{kcal} \cdot \mathrm{mol}^{-1}$.

Afterwards, two different routes have been hypothesized: (i) benzyl radical and Vradical complex (3) coupling, leading to V-complex (4); (ii) reaction between benzyl radical and molecular dioxygen in solution, to form benzyl peroxy radical.

In this context, DFT calculations have been carried out to predict the energetically favoured pathway. However, a direct comparison between the two possible routes is not appropriate, since very different species are involved.

Nevertheless, experimental data underline the key role of $\mathrm{O}_{2}$ for the successful outcome of the reaction: experiments performed under $\mathrm{N}_{2}$ atmosphere led to a remarkable yield drop-off, while under $\mathrm{O}_{2}$ a sensible improvement of benzaldehyde yield was detected.

As a matter of fact, DFT calculations revealed that benzyl radical reaction with dioxygen is energetically favored, being the activation energy barrier of about $0.6 \mathrm{kcal} \cdot \mathrm{mol}^{-1}$ (Figure 6). Consequently, benzyl peroxy radical formation is highly probable. Moreover, it can be speculated that reactions performed under $\mathrm{O}_{2}$ atmosphere are even more favored because of statistic reasons. 


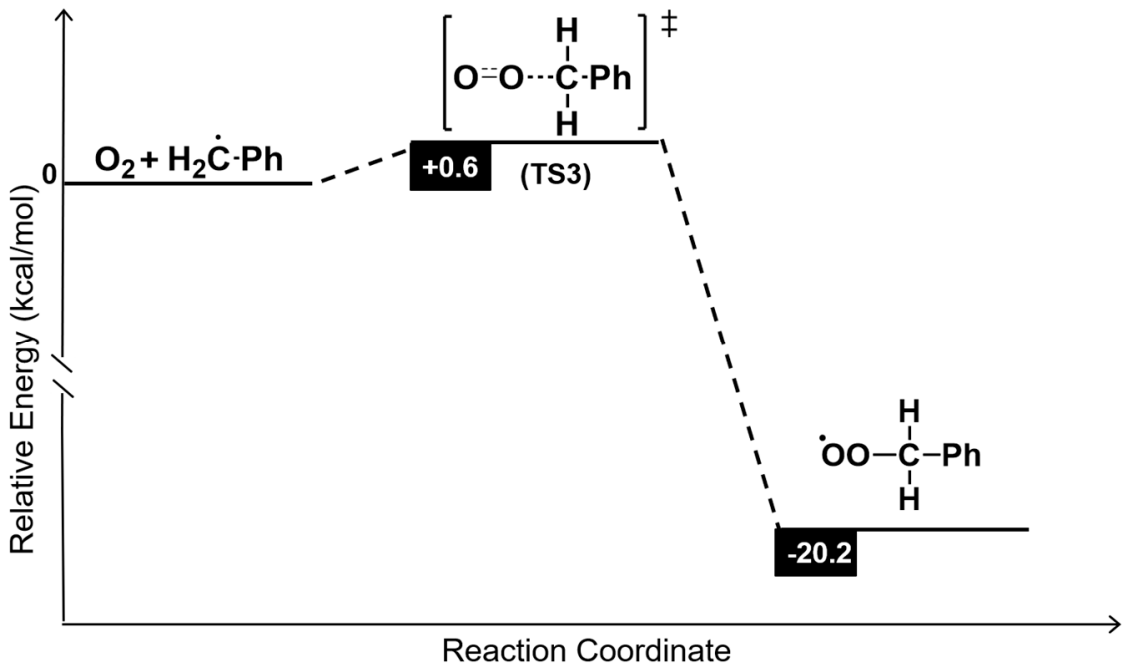

Figure 6. Relative energy diagram vs. reaction coordinate for TS3.

Conversely, coupling between benzyl radical and V-complex (3) appears energetically disfavoured and it would lead to complex (4), which cannot produce benzaldehyde.

To conclude, reaction of benzyl radical with $\mathrm{O}_{2}$ is pivotal in the process and it readily occurs in solution. Indeed, coupling between two benzyl peroxy radicals leads to a very unstable species that immediately disproportionates forming benzaldehyde, $\mathrm{O}_{2}$, and benzyl alcohol [45]. The latter, being more reactive than toluene, is easily converted to the aldehyde, as experimentally demonstrated.

\section{Materials and Methods}

All commercial reagents and solvents were purchased from Sigma Aldrich/Merck Life Science (KGaA, Darmstadt, Germany), with the highest degree of purity, and they were used without any further purification. UV-vis absorption spectra were recorded with a UV-Vis 2450 Shimadzu (Kyoto, Japan) spectrophotometer. GC-MS analyses have been performed with a Shimadzu (Kyoto, Japan) GCMS QP2010 Ultra system.

\subsection{Reactions in Biphasic System $\left(\mathrm{PhCH}_{3}: \mathrm{H}_{2} \mathrm{O} 1: 1 \mathrm{v} / \mathrm{v}\right)$}

In a $100 \mathrm{~mL}$ Erlenmeyer flask equipped with a condenser, ammonium vanadate, and the proper amount of KF were dissolved in $10 \mathrm{~mL}$ of distilled water. $10 \mathrm{~mL}$ of toluene (containing $2 \times 10^{-3} \mathrm{M}$ of decane as the internal standard) were added to the aqueous phase. $\mathrm{pH}$ was adjusted to 1 with $90 \mu \mathrm{L}$ of $10.8 \mathrm{M}$ perchloric acid. Afterwards, $\mathrm{H}_{2} \mathrm{O}_{2}$ was added to the mixture. The aqueous and organic solvent were kept under vigorous stirring $(1000 \mathrm{rpm})$ at $25^{\circ} \mathrm{C}$. At selected time, an aliquot of $100 \mu \mathrm{L}$ of the organic phase was taken, diluted with $100 \mu \mathrm{L}$ of $\mathrm{PhCH}_{3}$ and analyzed by GC-MS. Results are reported in Table 1 and Table 4.

\subsection{Reactions in $\mathrm{H}_{2} \mathrm{O}$ with a Stoichiometric Amount of Toluene}

In a $100 \mathrm{~mL}$ Erlenmeyer flask equipped with a condenser (or with a cap, when specified), ammonium vanadate and $14.5 \mathrm{mg}$ of $\mathrm{KF}(0.25 \mathrm{mmol})$ were dissolved in $10 \mathrm{~mL}$ of distilled water. Then, the proper amount of toluene was added to the aqueous solution, together with $90 \mu \mathrm{L}$ of $10.8 \mathrm{M}$ perchloric acid and $\mathrm{H}_{2} \mathrm{O}_{2}$. The mixture was stirred at $1000 \mathrm{rpm}$, at $25^{\circ} \mathrm{C}$. At selected time, reaction mixture was extracted with two portions of $5 \mathrm{~mL}$ of diethyl ether (containing decane $1 \times 10^{-3} \mathrm{M}$ as the internal standard). Organic phase was dried with $\mathrm{Na}_{2} \mathrm{SO}_{4}$ and $1 \mu \mathrm{L}$ of this solution was analyzed by GC-MS. Results are reported in Table 2 (entries 1-4). 


\subsection{Reactions in Biphasic System (Organic Solvent: $\mathrm{H}_{2} \mathrm{O}$ 1:1 v/v)}

In a $100 \mathrm{~mL}$ Erlenmeyer flask equipped with a condenser, ammonium vanadate and $14.5 \mathrm{mg}$ of KF $(0.25 \mathrm{mmol})$ were dissolved in $10 \mathrm{~mL}$ of distilled water. Then, $10 \mathrm{~mL}$ of the organic solvent (dichloromethane or cyclohexane) containing decane as internal standard were added to the mixture. Afterwards, toluene was added, together with $90 \mu \mathrm{L}$ of $10.8 \mathrm{M}$ perchloric acid and the proper amount of $\mathrm{H}_{2} \mathrm{O}_{2}$. The reaction was kept under stirring at $1000 \mathrm{rpm}$, at $25^{\circ} \mathrm{C}$. At selected time, $100 \mu \mathrm{L}$ of the organic phase were diluted with $100 \mu \mathrm{L}$ of the same solvent and analyzed by GC-MS. Results are reported in Table 2 (entries 5, 6).

\subsection{Reactions in Biphasic System (Ionic Liquid: $\mathrm{H}_{2} \mathrm{O}$ 1:10 v/v)}

In a $100 \mathrm{~mL}$ Erlenmeyer flask equipped with a condenser, ammonium vanadate and $14.5 \mathrm{mg}$ of KF $(0.25 \mathrm{mmol})$ were dissolved in $10 \mathrm{~mL}$ of distilled water. Then, $1 \mathrm{~mL}$ of [pmim] $\mathrm{Tf}_{2} \mathrm{~N}$ (synthesized according to a previously reported procedure) [38] was added in the flask. Afterwards, $50 \mu \mathrm{L}$ of toluene $(0.5 \mathrm{mmol}), 90 \mu \mathrm{L}$ of $10.8 \mathrm{M}$ perchloric acid and $\mathrm{H}_{2} \mathrm{O}_{2}$ were added and the reaction was kept under stirring at $1000 \mathrm{rpm}$, at $25^{\circ} \mathrm{C}$. After $24 \mathrm{~h}, 500 \mu \mathrm{L}$ of the ionic liquid were filtered over silica gel and diluted with $2 \mathrm{~mL}$ of dichloromethane containing the internal standard. $1 \mu \mathrm{L}$ of this solution was analyzed by GC-MS. Results are reported in Table 2 (entry 7).

\subsection{Reactions in Biphasic System ( $\mathrm{PhCH}_{3}: \mathrm{H}_{2} \mathrm{O} 1: 1$ v/v): Inorganic Salt Screening}

In a $100 \mathrm{~mL}$ Erlenmeyer flask equipped with a condenser, ammonium vanadate and $0.25 \mathrm{mmol}$ of selected halogenated inorganic salt were dissolved in $10 \mathrm{~mL}$ of distilled water. $10 \mathrm{~mL}$ of toluene (containing $2 \times 10^{-3} \mathrm{M}$ decane as internal standard) were added to the aqueous phase. $\mathrm{pH}$ was adjusted to 1 with $90 \mu \mathrm{L}$ of $10.8 \mathrm{M}$ perchloric acid. Afterwards, $\mathrm{H}_{2} \mathrm{O}_{2}$ was added to the mixture. The mixture was kept under vigorous stirring (1000 rpm) at $25^{\circ} \mathrm{C}$. At selected time, an aliquot of $100 \mu \mathrm{L}$ of the organic phase was taken, diluted with $100 \mu \mathrm{L}$ of $\mathrm{PhCH}_{3}$ and analyzed by GC-MS. Results are reported in Table 3.

\subsection{Reactions in Biphasic System $\left(\mathrm{PhCH}_{3}: \mathrm{H}_{2} \mathrm{O} 1: 1 \mathrm{v} / \mathrm{v}\right)$ under $\mathrm{O}_{2}$ Atmosphere}

In a $50 \mathrm{~mL}$ two-neck round bottom flask, ammonium vanadate and $\mathrm{KF}$ were dissolved in $10 \mathrm{~mL}$ of distilled water. $10 \mathrm{~mL}$ of toluene (containing $2 \times 10^{-3} \mathrm{M}$ decane as internal standard) were added to the aqueous phase. $\mathrm{pH}$ was adjusted to 1 with $90 \mu \mathrm{L}$ of $10.8 \mathrm{M}$ perchloric acid. Afterwards, $\mathrm{H}_{2} \mathrm{O}_{2}$ was added to the mixture. The mixture was bubbled with $\mathrm{O}_{2}$ for $30 \mathrm{~min}$ and kept under vigorous stirring (1000 rpm) at $25^{\circ} \mathrm{C}$ under $\mathrm{O}_{2}$ atmosphere. At selected time, an aliquot of $100 \mu \mathrm{L}$ of the organic phase was taken, diluted with $100 \mu \mathrm{L}$ of $\mathrm{PhCH}_{3}$ and analyzed by GC-MS. Results are reported in Table 5 .

\subsection{Reactions in Biphasic System ( $\left.\mathrm{PhCH}_{3}: \mathrm{H}_{2} \mathrm{O} 1: 1 \mathrm{v} / \mathrm{v}\right)$ at Different Temperatures}

In a $100 \mathrm{~mL}$ Erlenmeyer flask equipped with a condenser, ammonium vanadate and $14.5 \mathrm{mg}$ of KF $(0.25 \mathrm{mmol})$ were dissolved in $10 \mathrm{~mL}$ of distilled water. $10 \mathrm{~mL}$ of toluene (containing $2 \times 10^{-3} \mathrm{M}$ decane as internal standard) were added to the aqueous phase. $\mathrm{pH}$ was adjusted to 1 with $90 \mu \mathrm{L}$ of $10.8 \mathrm{M}$ perchloric acid. Afterwards, $\mathrm{H}_{2} \mathrm{O}_{2}$ was added to the mixture. The mixture was kept under vigorous stirring $(1000 \mathrm{rpm})$ at $25^{\circ} \mathrm{C}, 40^{\circ} \mathrm{C}$, and $60^{\circ} \mathrm{C}$. At $3.5 \mathrm{~h}, 7 \mathrm{~h}, 24 \mathrm{~h}$, and $72 \mathrm{~h}$ an aliquot of $100 \mu \mathrm{L}$ of the organic phase was taken, diluted with $100 \mu \mathrm{L}$ of $\mathrm{PhCH}_{3}$ and analyzed by GC-MS. Results are reported in Table S1.

\subsection{Reactions Reported in Biphasic System ( $\mathrm{PhCH}_{3}: \mathrm{H}_{2} \mathrm{O} \mathrm{1:1} \mathrm{v/v)} \mathrm{at} 60^{\circ} \mathrm{C}$}

In a $100 \mathrm{~mL}$ Erlenmeyer flask equipped with a condenser, ammonium vanadate and KF were dissolved in $10 \mathrm{~mL}$ of distilled water. $10 \mathrm{~mL}$ of toluene (containing $2 \times 10^{-3} \mathrm{M}$ decane as internal standard) were added to the aqueous phase. $\mathrm{pH}$ was adjusted to 1 with $90 \mu \mathrm{L}$ of $10.8 \mathrm{M}$ perchloric acid. Afterwards, $0.05 \mathrm{mmol}$ of $\mathrm{H}_{2} \mathrm{O}_{2}$ was added to the mixture. The mixture was kept under vigorous stirring $(1000 \mathrm{rpm})$ at $60^{\circ} \mathrm{C}$. At $24 \mathrm{~h}$ an aliquot of $100 \mu \mathrm{L}$ of the organic phase was taken, diluted with $100 \mu \mathrm{L}$ of $\mathrm{PhCH}_{3}$ and analyzed by GC-MS. Reactions Reported in Table 6 (entries 2 and 4). 


\subsection{Reactions in Biphasic System ( $\left.\mathrm{PhCH}_{3}: \mathrm{H}_{2} \mathrm{O} 1: 1 \mathrm{v} / \mathrm{v}\right)$ at $60{ }^{\circ} \mathrm{C}$, under $\mathrm{O} 2$ Atmosphere}

In a $50 \mathrm{~mL}$ two-neck round bottom flask, ammonium vanadate and $\mathrm{KF}$ were dissolved in $10 \mathrm{~mL}$ of distilled water. $10 \mathrm{~mL}$ of toluene (containing $2 \times 10^{-3} \mathrm{M}$ decane as internal standard) were added to the aqueous phase. $\mathrm{pH}$ was adjusted to 1 with $90 \mu \mathrm{L}$ of $10.8 \mathrm{M}$ perchloric acid. Afterwards, $\mathrm{H}_{2} \mathrm{O}_{2}(0.05 \mathrm{mmol})$ was added to the mixture. The mixture was bubbled with $\mathrm{O}_{2}$ for 30 minutes and kept under vigorous stirring $(1000 \mathrm{rpm})$ at $60^{\circ} \mathrm{C}$ under $\mathrm{O}_{2}$ atmosphere. At selected time, an aliquot of $100 \mu \mathrm{L}$ of the organic phase was taken, diluted with $100 \mu \mathrm{L}$ of $\mathrm{PhCH}_{3}$ and analyzed by GC-MS. Reactions Reported in Table 6 (entries 1 and 3).

\subsection{DFT Calculations}

DFT calculations have been performed using Gaussian 16 rev. A.03 (Gaussian, Inc., Wallingford CT, 2016) [50]. Geometry optimization of reagents, intermediates and transition states (TS) has been performed in the vacuum with B3LYP functional. 6-31G(d) basis set was used for $\mathrm{H}, \mathrm{C}$, and $\mathrm{O}$ atoms, while LanL2DZ basis set was adopted for vanadium. Transition state optimization was performed with TS and QTS3 option.

\section{Conclusions}

In this paper, a sustainable approach for the selective toluene oxidation to benzaldehyde has been presented. The oxidizing system includes a cheap and safe vanadium catalyst dissolved in an acid aqueous solution, and a benign oxidant, such as hydrogen peroxide. In order to develop a sustainable process, organic solvents have been avoided, so toluene is used as substrate and co-solvent at the same time. To note, the addition of KF or $\mathrm{O}_{2}$ atmosphere is pivotal to guarantee the success of the reaction.

The best results have been obtained performing the reaction at $25^{\circ} \mathrm{C}$ or $60{ }^{\circ} \mathrm{C}$, using $50 \%$ or $20 \%$ of the vanadium catalyst with respect to hydrogen peroxide, under $\mathrm{O}_{2}$ atmosphere. In such conditions, about $30 \%$ of benzaldehyde was formed in $24 \mathrm{~h}$. Despite such a result being in line with previously reported papers on toluene oxidation, here the most relevant feature is that the reaction is very selective, having never detected benzyl alcohol or benzoic acid. Moreover, the catalytic system is composed by safe and non-toxic materials, so hazardous reagents and solvents have been avoided, thus making it highly environmentally friendly.

Importantly, recycle of the reaction mixture was successfully achieved at least for four runs, with preservation of yield and selectivity. Notably, reactions performed at $60{ }^{\circ} \mathrm{C}$ showed a continuous production of benzaldehyde, with a constant round yield. At the end of the fourth round, $74 \times 10^{-3} \mathrm{mmol}$ of benzaldehyde were obtained, with an overall yield of $37 \%$. Such result opens the possibility to explore the application of flow-technique-i.e., continuous addition of reagents-thus allowing full conversion of toluene to benzaldehyde.

DFT calculations allowed to draw the energetic diagram of the reaction pathway. Results highlighted the fundamental role of $\mathrm{O}_{2}$, since, if not involved, reactions proceed through a non-productive route, that would not form benzaldehyde.

To conclude, considering the widespread interest in benzaldehyde production, the use of safe reagents and mild conditions, the remarkable selectivity, together with the opportunity to sensibly increase toluene conversion through subsequent batch processes, make the proposed system an appealing alternative to the currently adopted techniques related with the production of benzaldehyde.

Supplementary Materials: The following are available online at https://www.mdpi.com/2073 -4344/11/2/262/s1: Table S1: Toluene oxidation in a biphasic system $\mathrm{PhCH}_{3}-\mathrm{H}_{2} \mathrm{O}$. Conditions: $\mathrm{V}=20 \mathrm{~mL} ; \mathrm{PhCH}_{3}: \mathrm{H}_{2} \mathrm{O} 1: 1 \mathrm{v} / \mathrm{v}, \mathrm{pH}=1, \mathrm{H}_{2} \mathrm{O}_{2} 0.05 \mathrm{mmol}, \mathrm{NH}_{4} \mathrm{VO}_{3} 0.05 \mathrm{mmol}, \mathrm{KF}=0.25 \mathrm{mmol}$; Table S2: Recycle tests for the selective toluene oxidation to benzaldehyde under $\mathrm{O}_{2}$ atmosphere in a biphasic system $\mathrm{PhCH}_{3}-\mathrm{H}_{2} \mathrm{O}$. Conditions: $\mathrm{V}=20 \mathrm{~mL} ; \mathrm{PhCH}_{3}: \mathrm{H}_{2} \mathrm{O} 1: 1 \mathrm{v} / \mathrm{v}, \mathrm{pH}=1, \mathrm{H}_{2} \mathrm{O}_{2} 0.05$ mmol, $\mathrm{NH}_{4} \mathrm{VO}_{3} 0.025 \mathrm{mmol}$ at $25{ }^{\circ} \mathrm{C}$; Table S3: Recycle tests for the selective toluene oxidation to benzaldehyde under $\mathrm{O}_{2}$ atmosphere in a biphasic system $\mathrm{PhCH}_{3}-\mathrm{H}_{2} \mathrm{O}$. Conditions: $\mathrm{V}=20 \mathrm{~mL}$; $\mathrm{PhCH}_{3}: \mathrm{H}_{2} \mathrm{O} 1: 1 \mathrm{v} / \mathrm{v}, \mathrm{pH}=1, \mathrm{H}_{2} \mathrm{O}_{2} 0.05 \mathrm{mmol}, \mathrm{NH}_{4} \mathrm{VO}_{3} 0.01 \mathrm{mmol}$ at $60{ }^{\circ} \mathrm{C}$; Figure S1: UV-vis 
absorption spectra of V-monoperoxo complex in the presence of KF; Optimized cartesian coordinates (in Angstroms).

Author Contributions: Conceptualization, P.G.; Methodology, P.G., F.S., V.C., and F.V.; Validation, F.S., V.C., and G.P.; Formal analysis, F.V and G.F.; Investigation, F.V., F.S., and G.F.; Resources, P.G. and V.C.; Data curation, F.V. and F.S.; Writing—original draft preparation, F.V. and F.S.; Writing-review and editing, F.S.; Supervision, P.G. and V.C.; Project administration, P.G.; Funding acquisition, P.G. and F.S. All authors have read and agreed to the published version of the manuscript.

Funding: This research was funded by University of Rome Tor Vergata, grant HYPHOTOCAT project, "Beyond borders" and "B-LIGZYMES" project (RISE H2020).

Data Availability Statement: The data presented in this study are available on request from the corresponding author.

Acknowledgments: Massimo Bietti and Michela Salamone are gratefully acknowledged for the use of GC for preliminary analyses and for helpful discussion.

Conflicts of Interest: The authors declare no conflict of interest.

\section{References}

1. Kesavan, L.; Tiruvalam, R.; Rahim, M.H.A.; Bin Saiman, M.I.; Enache, D.I.; Jenkins, R.L.; Dimitratos, N.; Lopez-Sanchez, J.A.; Taylor, S.H.; Knight, D.W. Solvent-Free Oxidation of Primary Carbon-Hydrogen Bonds in Toluene Using Au-Pd Alloy Nanoparticles. Science 2011, 331, 195-199. [CrossRef]

2. Acharyya, S.S.; Ghosh, S.; Tiwari, R.; Sarkar, B.; Kumar, R.; Pendem, C.; Sasaki, T.; Bal, R. Preparation of $\mathrm{CuCr}_{2} \mathrm{O}_{4} \mathrm{Spinel}$ Nanoparticles Catalyst for Selective Oxidation of Toluene to Benzaldehyde. Green Chem. 2014, 16, 2500-2508. [CrossRef]

3. Mal, D.D.; Khilari, S.; Pradhan, D. Efficient and Selective Oxidation of Toluene to Benzaldehyde on Manganese Tungstate Nanobars: A Noble Metal-Free Approach. Green Chem. 2018, 20, 2279-2289. [CrossRef]

4. Dionisio, A.P.; Molina, G.; Souza de Carvalho, D.; dos Santos, R.; Bicas, J.L.; Pastore, G.M. Natural Food Additives, Ingredients and Flavourings, Chapter 11. In Natural Flavourings from Biotechnology for Foods and Beverages; Woodhead Publishing: Shaston, UK, 2012.

5. Pugh, S.; McKenna, R.; Halloum, I.; Nielsen, D.R. Engineering Escherichia Coli for Renewable Benzyl Alcohol Production. Metab. Eng. Commun. 2015, 2, 39-45. [CrossRef]

6. Wheeler, O.H. Étard reaction: I. its scope and limitation with substituted toluenes. Can. J. Chem. 1958, 36, 667-671. [CrossRef]

7. Partenheimer, W. Methodology and Scope of Metal/Bromide Autoxidation of Hydrocarbons. Catal. Today 1995, 23, 69-158. [CrossRef]

8. Partenheimer, W. The High Yield Synthesis of Benzaldehydes from Benzylic Alcohols Using Homogeneously Catalyzed Aerobic Oxidation in Acetic Acid. Adv. Synth. Catal. 2006, 348, 559-568. [CrossRef]

9. Lu, B.; Cai, N.; Sun, J.; Wang, X.; Li, X.; Zhao, J.; Cai, Q. Solvent-Free Oxidation of Toluene in an Ionic Liquid with $\mathrm{H}_{2} \mathrm{O}_{2}$ as Oxidant. Chem. Eng. J. 2013, 225, 266-270. [CrossRef]

10. Guajardo, N.; Carlesi, C.; Aracena, Á. Toluene Oxidation by Hydrogen Peroxide in Deep Eutectic Solvents. Chem CatChem 2015, 7, 2451-2454. [CrossRef]

11. Pembere, A.M.S.; Cui, C.; Anumula, R.; Wu, H.; An, P.; Liang, T.; Luo, Z. A Hexagonal Ni 6 Cluster Protected by 2-Phenylethanethiol for Catalytic Conversion of Toluene to Benzaldehyde. Phys. Chem. Chem. Phys. 2019, 21, 17933-17938. [CrossRef]

12. Xu, C.; Wang, X.; Chen, Y.; Dai, L. Synergistic Effect between Cu-Cr Bimetallic Oxides Supported on g- $\mathrm{C}_{3} \mathrm{~N}_{4}$ for the Selective Oxidation of Toluene to Benzaldehyde. Catal. Sci. Technol. 2019, 9, 4441-4450. [CrossRef]

13. Paul, P.; Ghosh, A.; Chatterjee, S.; Bera, A.; Alam, S.M.; Islam, S.M. Development of a Polymer Embedded Reusable Heterogeneous Oxovanadium(IV) Catalyst for Selective Oxidation of Aromatic Alkanes and Alkenes Using Green Oxidant. Inorg. Chim. Acta 2019, 492, 198-212. [CrossRef]

14. Shi, G.; Xu, S.; Bao, Y.; Xu, J.; Liang, Y. Selective Aerobic Oxidation of Toluene to Benzaldehyde on Immobilized CoOx on SiO 2 Catalyst in the Presence of N-Hydroxyphthalimide and Hexafluoropropan-2-ol. Catal. Commun. 2019, 123, 73-78. [CrossRef]

15. Song, L.-N.; Ding, F.; Yang, Y.-K.; Ding, D.; Chen, L.; Au, C.-T.; Yin, S.-F. Synthesis of $\mathrm{TiO}_{2} / \mathrm{Bi}_{2} \mathrm{MoO}_{6}$ Composite for Partial Oxidation of Aromatic Alkanes under Visible-Light Illumination. ACS Sustain. Chem. Eng. 2018, 6, 17044-17050. [CrossRef]

16. Yuan, B.; Zhang, B.; Wang, Z.; Lu, S.; Li, J.; Liu, Y.; Li, C. Photocatalytic Aerobic Oxidation of Toluene and Its Derivatives to Aldehydes on $\mathrm{Pd} / \mathrm{Bi}_{2} \mathrm{WO}_{6}$. Chin. J. Catal. 2017, 38, 440-446. [CrossRef]

17. Zhu, Y.; Zhu, Y.; Zeng, H.; Chen, Z.; Little, R.D.; Ma, C. A Promising Electro-Oxidation of Methyl-Substituted Aromatic Compounds to Aldehydes in Aqueous Imidazole Ionic Liquid Solutions. J. Electroanal. Chem. 2015, 751, 105-110. [CrossRef]

18. Silva, G.C.; Carvalho, N.M.F.; Horn, A.; Lachter, E.R.; Antunes, O.A.C. Oxidation of Aromatic Compounds by Hydrogen Peroxide Catalyzed by Mononuclear Iron(III) Complexes. J. Mol. Catal. A Chem. 2017, 426, 564-571. [CrossRef] 
19. Chen, H.-Y.; Lv, M.; Zhou, X.-T.; Wang, J.-X.; Han, Q.; Ji, H.-B. A Novel System Comprising Metalloporphyrins and Cyclohexene for the Biomimetic Aerobic Oxidation of Toluene. Catal. Commun. 2018, 109, 76-79. [CrossRef]

20. Xia, H.; Liu, Z.; Xu, Y.; Zuo, J.; Qin, Z. Highly Efficient V-Mo-Fe-O Catalysts for Selective Oxidation of Toluene to Benzaldehyde. Catal. Commun. 2016, 86, 72-76. [CrossRef]

21. Deng, W.; Wan, Y.; Jiang, H.; Luo, W.-P.; Tan, Z.; Jiang, Q.; Guo, C.-C. Solvent-Free Aerobic Oxidation of Toluene over Metalloporphyrin/NHPI/CTAB: Synergy and Mechanism. Catal. Lett. 2014, 144, 333-339. [CrossRef]

22. Maurya, M.R.; Sarkar, B.; Kumar, A.; Ribeiro, N.; Miliute, A.; Pessoa, J.C. New Thiosemicarbazide and Dithiocarbazate Based Oxidovanadium (IV) and Dioxidovanadium (V) Complexes. Reactivity and Catalytic Potential. New J. Chem. 2019, 43, 17620-17635. [CrossRef]

23. Wang, X.; Cao, X.; Hu, X.; Li, G.; Zhu, L.; Hu, C. Effect of Zirconium Addition on Vanadium-Catalyzed Toluene Oxidation by $\mathrm{H}_{2} \mathrm{O}_{2}$ in $\mathrm{CH}_{3} \mathrm{COOH}$. J. Mol. Catal. A Chem. 2012, 357, 1-10. [CrossRef]

24. Wu, X.; Deng, Z.; Yan, J.; Zhang, F.; Zhang, Z. Effect of Acetic Anhydride on the Oxidation of Toluene to Benzaldehyde with Metal/Bromide Catalysts. Ind. Eng. Chem. Res. 2014, 53, 14601-14606. [CrossRef]

25. Feng, J.-B.; Wu, X.-F. Transition Metal-Catalyzed Oxidative Transformations of Methylarenes: Transition Metal-Catalyzed Oxidative Transformations of Methylarenes. Appl. Organometal. Chem. 2015, 29, 63-86. [CrossRef]

26. Gaster, E.; Kozuch, S.; Pappo, D. Selective Aerobic Oxidation of Methylarenes to Benzaldehydes Catalyzed by N-Hydroxyphthalimide and Cobalt(II) Acetate in Hexafluoropropan-2-ol. Angew. Chem. Int. Ed. 2017, 56, 5912-5915. [CrossRef]

27. Galloni, P.; Mancini, M.; Floris, B.; Conte, V. A Sustainable Two-Phase Procedure for V-Catalyzed Toluene Oxidative Bromination with $\mathrm{H}_{2} \mathrm{O}_{2}-\mathrm{KBr}$. Dalton Trans. 2013, 42, 11963-11970. [CrossRef]

28. Rehder, D. The role of vanadium in biology. Metallomics 2015, 7, 730-742. [CrossRef]

29. Kaim, W.; Schwederski, B.; Klein, A. Bioinorganic Chemistry_Inorganic Elements in the Chemistry of Life: An Introduction and Guide, 2nd ed.; John Wiley \& Sons, Ltd.: Hoboken, NJ, USA, 2013.

30. Conte, V.; Floris, B. Vanadium Catalyzed Oxidation with Hydrogen Peroxide. Inorg. Chim. Acta 2010, 363, 1935-1946. [CrossRef]

31. Conte, V.; Floris, B. Vanadium and Molybdenum Peroxides: Synthesis and Catalytic Activity in Oxidation Reactions. Dalton Trans. 2011, 40, 1419-1436. [CrossRef] [PubMed]

32. Floris, B.; Sabuzi, F.; Coletti, A.; Conte, V. Sustainable Vanadium-Catalyzed Oxidation of Organic Substrates with $\mathrm{H}_{2} \mathrm{O}_{2}$. Catal. Today 2017, 285, 49-56. [CrossRef]

33. Langeslay, R.R.; Kaphan, D.M.; Marshall, C.L.; Stair, P.C.; Sattelberger, A.P.; Delferro, M. Catalytic Applications of Vanadium: A Mechanistic Perspective. Chem. Rev. 2019, 119, 2128-2191. [CrossRef]

34. Sabuzi, F.; Pomarico, G.; Conte, V.; Galloni, P. Peroxo-Vanadium Complexes as Sustainable Catalysts in Oxidations, Halogenations and Other Organic Transformations. In Vanadium Catalysis; Sutradhar, M., da Silva, J.A.L., Pombeiro, A.J.L., Eds.; Royal Society of Chemistry: London, UK, 2021; Chapter 5; pp. 97-110.

35. Sabuzi, F.; Pomarico, G.; Floris, B.; Valentini, F.; Galloni, P.; Conte, V. Sustainable Bromination of Organic Compounds: A Critical Review. Coordin. Chem. Rev. 2019, 385, 100-136. [CrossRef]

36. Penín, L.; Gigli, M.; Sabuzi, F.; Santos, V.; Galloni, P.; Conte, V.; Parajó, J.C.; Lange, H.; Crestini, C. Biomimetic Vanadate and Molybdate Systems for Oxidative Upgrading of Iono- and Organosolv Hard- and Softwood Lignins. Processes 2020, 8, 1161. [CrossRef]

37. Sabuzi, F.; Churakova, E.; Galloni, P.; Wever, R.; Hollmann, F.; Floris, B.; Conte, V. Thymol Bromination-A Comparison between Enzymatic and Chemical Catalysis. Eur. J. Inorg. Chem. 2015, 3519-3525. [CrossRef]

38. Coletti, A.; Sabuzi, F.; Floris, B.; Galloni, P.; Conte, V. Efficient and Sustainable V-Catalyzed Oxidative Desulfurization of Fuels Assisted by Ionic Liquids. J. Fuel Chem. Technol. 2018, 46, 1121-1129. [CrossRef]

39. Floris, B.; Sabuzi, F.; Galloni, P.; Conte, V. The Beneficial Sinergy of MW Irradiation and Ionic Liquids in Catalysis of Organic Reactions. Catalysts 2017, 7, 261. [CrossRef]

40. Dai, C.; Zhang, J.; Huang, C.; Lei, Z. Ionic Liquids in Selective Oxidation: Catalysts and Solvents. Chem. Rev. 2017, 117, 6929-6983. [CrossRef] [PubMed]

41. Ceres, G.; Conte, V.; Mirruzzo, V.; Kolar, J.; Strlič, M. Imidazolium-Based Ionic Liquids for the Efficient Treatment of Iron Gall Inked Papers. ChemSusChem 2008, 1, 921-926. [CrossRef]

42. Bonchio, M.; Conte, V.; Di Furia, F.; Modena, G.; Moro, S.; Edwards, J.O. Nature of the Radical Intermediates in the Decomposition of Peroxovanadium Species in Protic and Aprotic Media. Inorg. Chem. 1994, 33, 1631-1637. [CrossRef]

43. Bortolini, O.; Conte, V. Vanadium (V) Peroxocomplexes: Structure, Chemistry and Biological Implications. J. Inorg. Biochem. 2005, 99, 1549-1557. [CrossRef]

44. Conte, V.; Coletti, A.; Floris, B.; Licini, G.; Zonta, C. Mechanistic Aspects of Vanadium Catalysed Oxidations with Peroxides. Coord. Chem. Rev. 2011, 255, 2165-2177. [CrossRef]

45. Ohkubo, K.; Mizushima, K.; Iwata, R.; Souma, K.; Suzuki, N.; Fukuzumi, S. Simultaneous Production of $p$-Tolualdehyde and Hydrogen Peroxide in Photocatalytic Oxygenation of $p$-Xylene and Reduction of Oxygen with 9-Mesityl-10-Methylacridinium Ion Derivatives. Chem. Commun. 2010, 46, 601-603. [CrossRef]

46. Chakravorti, M.C.; Saricar, A.R. Studies on Oxoperoxofluorovanadates (V). J. Fluor. Chem 1976, 8, 255-262. [CrossRef]

47. Schwendt, P.; Joniakova, D. Fluorooxoperoxo Complexes of Vanadium (V). Polyhedron 1984, 3, 287-290. [CrossRef] 
48. Damoyi, N.E. A DFT Mechanistic Study of the ODH of n-Hexane over Isolated $\mathrm{H}_{3} \mathrm{VO}_{4}$. Mol. Catal. 2018, 452, 83-92. [CrossRef]

49. Bagno, A.; Conte, V.; Di Furia, F.; Moro, S. Ab Initio Calculations on Water-Peroxovanadium Clusters, $\mathrm{VO}\left(\mathrm{O}_{2}\right)\left(\mathrm{H}_{2} \mathrm{O}\right)_{\mathrm{n}}{ }^{+}(\mathrm{n}=1-5)$. Implications for the Structure in Aqueous Solution. J. Phys. Chem. A 1997, 101, 4637-4640. [CrossRef]

50. Frisch, M.J.; Trucks, G.W.; Schlegel, H.B.; Scuseria, G.E.; Robb, M.A.; Cheeseman, J.R.; Scalmani, G.; Barone, V.; Petersson, G.A.; Nakatsuji, H.; et al. Gaussian 16, Revision A.03; Gaussian, Inc.: Wallingford, CT, USA, 2016. 